\title{
Long non-coding RNAs on the stage of cervical cancer (Review)
}

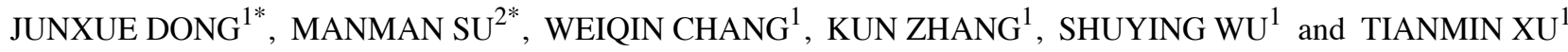 \\ ${ }^{1}$ Second Affiliated Hospital and ${ }^{2}$ College of Pharmacy, Jilin University, Changchun, Jilin 130000, P.R. China
}

Received February 12, 2017; Accepted July 17, 2017

DOI: 10.3892/or.2017.5905

\begin{abstract}
Cervical cancer is one of most malignant gynecological tumors. However, effective means for diagnosing and treating cervical cancer have yet to be identified. A few decades ago, long non-coding RNAs (lncRNAs) were regarded as useless parts of the genome, however, increasing data have demonstrated the importance of lncRNAs in the diagnosis and treatment of cervical cancers. The aim of the present study is to summarize the role(s) of HOTAIR, MALAT1, CCAT2, SPRY4-IT1, RSU1P2, CCHE1, IncRNA-EBIC and PVT1. Approximately 14 lncRNAs are involved in cervical cancer and several important proteins, miRNAs and other molecules and play crucial roles in a few traditional signaling pathways that have been proven to be related to those lncRNAs. In conclusion, lncRNAs may be useful as exact treatment targets and diagnostic biomarkers for improving therapies in cervical cancer patients and lncRNAs may contribute to effective diagnosis and treatment methods for cervical cancer.
\end{abstract}

\section{Contents}

1. Inroduction

2. Modes of interaction between lncRNAs and molecules

3. Functional lncRNAs involved in cervical cancer

4. IncRNAs may act as circulating tumor biomarkers

5. Conclusion and prospective

\section{Introduction}

Long non-coding RNA (lncRNA) is a type of non-coding RNA (ncRNA) that is comprised of over 200 nucleotides (nt)

Correspondence to: $\mathrm{Dr}$ Tianmin $\mathrm{Xu}$, Department of Obstetrics and Gynecology, The Second Hospital, Jilin University, $218 \mathrm{Zi}$ Qiang Street, Changchun, Jilin 130000, P.R. China

E-mail: xutianmin@126.com

${ }^{*}$ Contributed equally

Key words: cervical cancer, long non-coding RNA, biological function, regulatory mechanism, tumorigenesis and lacks an open reading region and the capacity for protein coding (1). More than $70 \%$ of the human genome has been transcribed into ncRNAs (2). In addition to lncRNAs, other ncRNAs have been identified, such as microRNAs (miRNA), which are small interfering RNAs (siRNA) made up of 20-24 nucleotides. miRNA was the first ncRNA found, though recently lncRNA has garnered more attention. It has been demonstrated that lncRNAs play crucial roles by influencing and changing cell growth, survival, cell cycle, differentiation and apoptosis; they also play a vital part in many diseases, including cancer (3). However, despite the above findings, the biological functions and molecular mechanisms of lncRNAs remain largely unknown (4). Utilizing next generation sequencing (NGS), three generations of sequencing, RNA-Seq, RIP-Seq and RNA array, the biological functions of lncRNAs could be gradually discovered (5), which would be indispensable for optimizing diagnostic and treatment methods for cervical cancer patients.

Cervical cancer is one of the most serious cancers. Each year, there are approximately 500,000 newly diagnosed cases, and 200,000 deaths due to cervical cancer occur worldwide (6). Without appropriate early diagnostic methods, particularly in developing areas, cervical cancer has developed into invasive cancers in a large number of patients, which has led to lower survival rates (7). Traditional radiotherapy and chemotherapy are still the most common therapies for the treatment of advanced cervical cancer; however, these methods are not always effective and can cause severe side-effects $(8,9)$. Therefore, it is urgent that biomarkers and novel treatment targets are found for effective diagnosis and treatment of cervical cancer. Many lncRNAs have been shown to be molecular regulatory factors in cancer and may provide therapeutic targets for improving survival in cases of cervical cancer. In this review, these aspects are explored: the interaction between IncRNAs and miRNA, and the molecular mechanisms involved; the interactions among the proteins (or the mRNAs encoding these proteins at the protein or transcriptome levels). In addition, an overview of research done on the function of lncRNAs in cervical cancer is provided along with prospective clinical applications of lncRNAs in cervical cancer.

\section{Modes of interaction between IncRNAs and molecules}

Studies of lncRNA molecular mechanisms have shown that lncRNAs are related to tumorigenesis (10). IncRNAs interact 


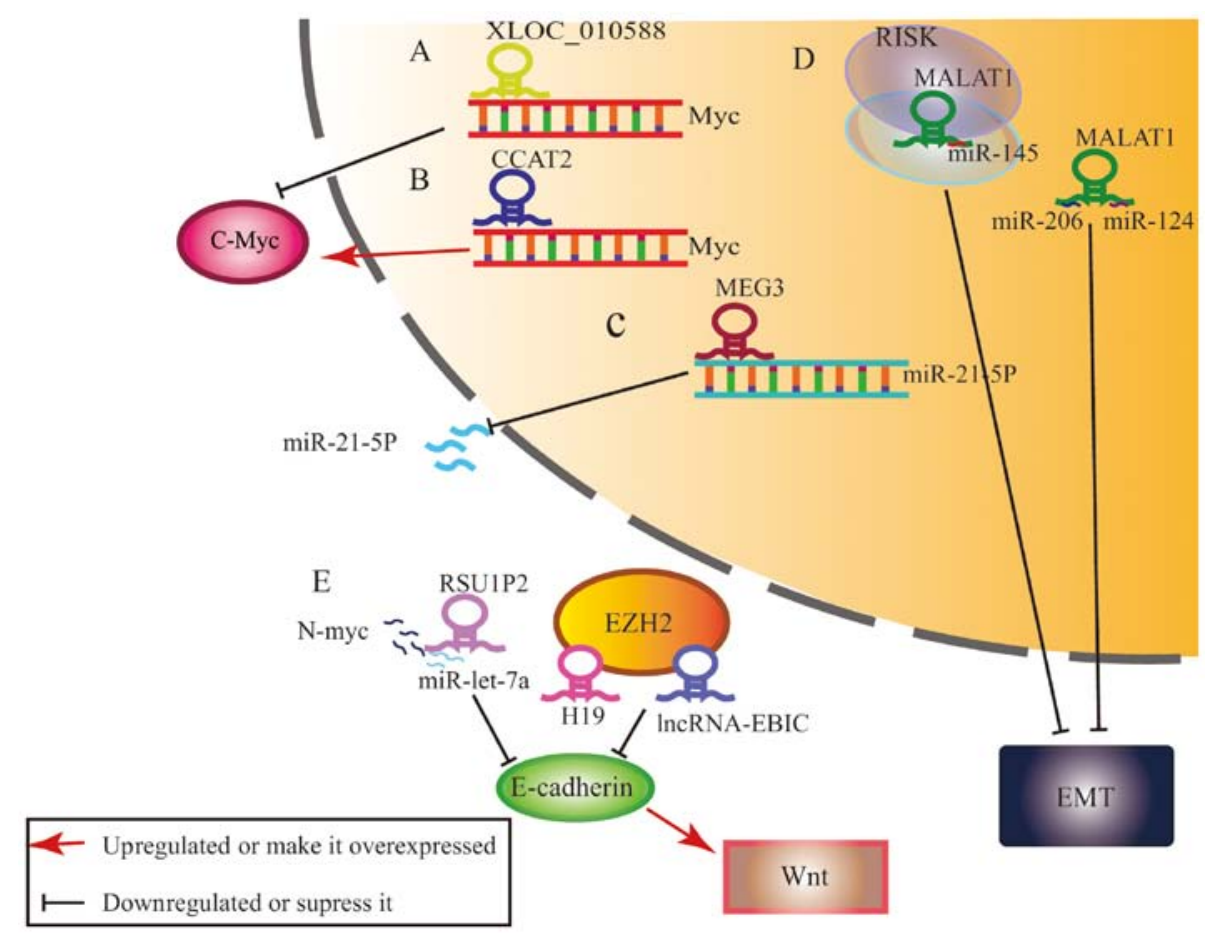

Figure 1. Interaction modes between IncRNAs and molecules. A, XLOC_010588 can suppress C-Myc expression. B, CCAT2 upregulates C-Myc. C-Myc is an oncoprotein that is upregulated in cervical cancer. C, MEG3 downregulates miR-21-5p, which inhibits the biological behavior of cervical cancer. D, MALAT1 sponges miR-124, miR-145 and miR-375 to promote malignant behavior of cervical cancer by inhibition of EMT (epithelial mesenchymal transition). It has been proven that MALAT1 and miR-145 are in the RISC complex. E, Three lncRNAs (lncRNA-EBIC, H19 and RSU1P2) can lower E-cadherin expression, which upregulates the downstream factor, Wnt. lncRNA-EBIC and H19 combined with EZH2. N-myc and miR-let-7a combine with RSU1P2 competitively, RSU1P2 behaves as a ceRNA and thus decreases the amount of miR-let-7a.

with proteins, miRNAs and mRNAs, developing complex mechanistic networks during tumor growth (11). Therefore, clarifying how lncRNAs regulate the process of gene transcription and post-transcription can lead to a better understanding of the pathogenesis of cervical cancer.

lncRNAs-proteins/mRNAs. Cervical cancer-related lncRNAs have been demonstrated to directly bind to target proteins or mRNAs to conduct post-transcriptional modification. Reportedly, lncRNA HOXA11-AS is involved in carcinogenesis through regulating the expression of HOXA11 (12). Besides, IncRNA-TI17313 was named lncRNA-EBIC, due to the fact that it is an EZH2-binding lncRNA in cervical cancer (13). EZH2 is an important member of PRC2, which is involved in several important regulatory mechanisms in cancer. Besides lncRNAEBIC other lncRNAs, such as HOTAIR, lncRNA-HEIH PVT1 and H19 have been shown to bind to EZH2 and take part in cancer epigenome modulation (14-17). Tseng et al (18) shows gain of PVT1 long non-coding RNA expression was required for high MYC protein levels in 8q24-amplified human cancer cells. PVT1 RNA and MYC protein expression correlated in primary human tumours, and copy number of PVT1 was co-increased in $>98 \%$ of MYC-copy-increase cancers. C-Myc is an oncoprotein, which is upregulated in cervical cancer $(19,20)$. C-Myc acts as a downstream effector of XLOC_010588, CCAT2 and RSU1P2 (21-23) and can also bind and stabilize the Myc via inhibiting its phosphorylation at threonine 58 (24). E-cadherin expression is repressed in cancer and has been found to be upregulated by MALAT1, but repressed by IncRNA-EBIC (25). In addition, IncRNA-
CCHE1 increases the expression of PCNA in cervical cancer by associating with PCNA mRNA (26). These studies illustrate that lncRNAs play a role in cervical cancer by interacting with mRNAs and/or proteins.

lncRNAs-miRNAs/circRNA. Since the function of competing endogenous RNA (ceRNA) was discovered, lncRNAs have been regarded as one of the most striking ceRNA and 'talk' to mRNAs or transcribed pseudogenes using microRNA response elements (MREs) as letters (27). lncRNAs work as 'miRNA sponges', which inhibit normal miRNAs targeting vitality on mRNAs (28-30). It has been reported that MEG3 acts as a cancer suppressor via lessening the expression of miR-21-5p in cervical cancer, in vitro (31). MALAT1 sponges miR-124, miR-145 and miR-375 promote the malignant behavior of cervical cancer (32-34). In other cancers, H19 has been shown to react with miR-675, miR-140 and miR-200, sponges circRNA MYLK and binds competitively with miRNA-29a-3p to suppress cervical cancer (35-38). These findings demonstrate the interactions between lncRNAs, miRNAs and circRNAs in cervical cancer.

lncRNA-HPV. Human papillomavirus (HPV) infection is a critical factor in the development of cervical cancer $(39,40)$ and highest risk of developing cervical cancer come from HPV type 16 and 18 (41,42). Moreover, some studies have suggested that lncRNAs and miRNAs play significant roles in the progression of cervical cancer by sponging the miRNAs combined with HPV proteins. Other studies have shown evidence of crosstalk between the HPV16 E7 oncoprotein 
and lncRNA, such as HOTAIR (43). Increasing evidence suggests that miRNAs-HPV protein like miR-135a-E6/E7 has an important function in cervical cancer (44). Because of the significance of HPV proteins in cervical cancer oncogenicity, finding effective lncRNAs that inhibit HPV protein transcription and translation is necessary (Fig. 1).

\section{Functional IncRNAs involved in cervical cancer}

HOTAIR. HOTAIR is one of most well-studied lncRNAs in cervical cancer. It is $2.2 \mathrm{~kb}$ expressed from the HOXC cluster located in chromosome 12q13.3 (45). In patients with invasive FIGO stage IA-IVB cervical cancer, it was found to be an independent prognostic factor for reduced survival. Furthermore, higher HOTAIR levels have been observed in malignant tissue compared with normal cervix tissue $(46,47)$. A case-control study, including 510 cervical cancer patients (cases) and 713 none-cancer individuals (controls), further indicated that the rs920778T allele conferred elevated HOTAIR transcriptional activity, thus, increasing the risk of developing cervical cancer (48). In addition, rs $2366152 \mathrm{C}$ was significantly over-represented and affected HOTAIR expression in HPV16-positive cervical cancer cases (49). Another study demonstrated that HOTAIR and HPV16 E7 (oncoprotein HPV E7 is the major transforming agent, which leads to carcinogenesis) strongly interact with each other, but not through the PRC2-complex (a complex that is related to a large number of lncRNAs) (43). The mammalian target of rapamycin (mTOR) has emerged as an important effector in cell-signaling pathways (50). Zhang et al (51), found that HOTAIR overexpression upregulates the mTOR pathway in cervical carcinoma cells. A higher level of HOTAIR was detected in the serum from cervical patients compared to normal women, indicating that HOTAIR may be a useful new circulating biomarker in serum. The study also showed that HOTAIR overexpression promoted cervical cancer cell growth, invasion and migration and that HOTAIR knockdown increased cell apoptosis, via the epithelial-mesenchymal transition (EMT) and Notch signaling pathways (52). In a study by Kim et al (46), HOTAIR overexpression in SiHa cells and cervical cancer tissue promoted VEGF and $\mathrm{mmP}-9$ protein expression. VEGF and mmP-9 not only play critical roles in the malignant behavior of cervical cancer, but knockdown of HOTAIR upregulates p21 and increases the radio-sensitivity of HeLa cells (53). Many other studies have found that HOTAIR was able to silence some tumor suppressors, such as HOXD10, PTEN and RBM38 and activate some significant signaling pathways, like STAT3, wnt/ $\beta$-catenin and PI3K/AKT (54-58).

H19. H19 is involved in many kinds of cancer, including ovarian, lung cancer and hepatocellular carcinoma. In spite of this, fewer studies have been done examining the relationship between $\mathrm{H} 19$ and cervical cancer than in investigating the relationship between HOTAIR and cervical cancer. Under normal conditions, only fetal tissue and adult muscle express H19, thus it often functions as ncRNA (59). H19 is upregulated in various human cancers, including bladder and breast cancer, and in lung carcinoma cells suggesting an oncogenic function (60). Conversely, in hepatocellular carci- noma, H19-mediated metastasis is suppressed by epigenetic activation of miR-200 suggesting that $\mathrm{H} 19$ may function to suppress cancer $(35,61,62)$. In ovarian cancer, H19 upregulates SLUG expression via miR-675, suppressing E-cadherin and activating EMT (36). Kim et al (63), explained that in cervical cancer, H19 and IGF2 are expressed abnormally and that this abnormal expression might be associated with the progression of cervical cancer.

XLOC_010588. XLOC_010588 is a 1950nt lncRNA, which has thus far been described in only one publication. It is located in chr13 on the downstream side of TGF $\beta$-stimulated clone-22 (TSC-22). Studies have found that TSC-22 has DNA binding sites and acts as a tumor suppressor. It inferred that XLOC_010588 may suppress the invasive behavior of cancer as well. They found that XLOC_010588 expression suppressed the progression of hepatocellular carcinoma, gastric, colon, breast, cervical and ovarian cancer. In addition, they found that XLOC_010588 inhibited the proliferation of cervical cancer cells via downregulating the expression of oncoprotein c-Myc (21).

MALAT1. Metastasis-associated lung adenocarcinoma transcript 1 (MALAT1) was first mentioned in association with lung cancer, but has now been found to be largely expressed in most cancers, working as a decoy for splicing factors leading to splicing malfunctioning (64). It has been demonstrated that there is a reciprocal regulation between miR-375 and MALAT1 through suppression of the EMT pathway. MALAT1 also acts as an miR-206 sponge (34). It has also been shown that downregulating MALAT1 in CaSki, HeLa and SiHa cells, as well as in cervical cancer tissues, weakens cancer cell invasion and metastasis by inhibiting EMT and regulation of the MALAT1-miR-124-RBG2 axis $(25,33)$. MALAT1 expression is an independent prognostic factor in addition to tumor size, FIGO stage and lymph node metastasis (65). In radiotherapy to treat cervical cancer, MALAT1 may result in radioresistance by working as a miR-145 sponge (32).

CCAT2. CCAT2 has been shown to be overexpressed in breast cancer and high levels of CCAT2 indicate poor prognosis and CMF adjuvant chemoresistance (66). CCAT2 has also been found to be upregulated in cervical cancer cells and tissues. In HeLa, CaSki and SiHa cervical cancer cells, CCAT2 knockdown inhibits cervical cancer cell proliferation at the G1 phase and triggers cell apoptosis $(22,67)$. However, high CCAT2 expression is indicative of a more advanced FIGO stage, lymph node metastasis and deep cervical invasion and lower survival (68).

SPRY4-IT1. SPRY4-IT1 is an unspliced, polyadenylated $687 \mathrm{nt} 4$ transcript derived from the second intron of the SPRY4 gene. Its potential for carcinogenesis was first $(69,70)$ found in melanoma and high levels of SPRY4-IT1 have since been confirmed in gastric, non-small cell lung cancer (NSCLC), esophageal squamous cell carcinoma (ESCC) and other cancers (71-76). Cao et al (77), showed that SPRY4-IT1 expression is a good candidate marker for discriminating between tumor tissue and normal tissue and for predicting poor prognoses in patients with cervical cancer. 
GAS5. GAS5 has been frequently reported in non-small cell lung cancer (78). GAS5 contributes to the proliferation and apoptosis of lung cancer cells and is indicative of poor prognoses in lung cancer patients. Furthermore, Liang et al (79), found lower levels of GAS5 in the plasma of patients with nonsmall cell lung cancer compared with healthy controls and, based on these results, suggested that GAS5 may represent a novel prognostic indicator and a target for gene therapy in non-small cell lung cancer. In gastric cancer cells, downregulation of GAS5 affects adriamycin sensitivity by promoting hypermethylation (80). It has been demonstrated that downregulation of GAS5 expression in human cervical cancer tissue is associated with poor prognoses in patients. It has also been reported that iRNA-mediated knockdown of GAS5 significantly increases proliferation, migration and invasion capability of cervical cancer cells compared with control cells, which suggests that GAS5 affects the tumorigenesis and progression of cervical cancer (81).

RSU1P2. Ras suppressor protein 1 pseudogene 2 (RSU1P2) upregulation promotes the malignant phenotype of cervical cancer. It was revealed that RSU1P2 acts as a ceRNA of miRNA let-7a and regulates IGF1R and N-myc expression. The transcription factor, $\mathrm{N}$-myc forms a positive feedback loop with RSU1P2, in turn activating its expression (23). To the best of our knowledge, the N-myc positive feedback loop has not been reported in studies of other types of cancer and requires further research.

CCHE1. CCHE1 is located in an intergenic region on chromatin 10 . It physically binds to proliferating cell nuclear antigen (PCNA) mRNA and upregulates PCNA expression, which promotes the proliferation of cervical cancer cells. In contrast, decreasing the CCHE1 level via RNA pull-down assays inhibits the proliferation of cervical cancer cells. The present review also report that higher CCHE1 expression was significantly associated with large tumor size, advanced FIGO stage, invasion and low survival (26). There is a similar phenomenon, which occurs in hepatocellular carcinoma. Peng et al (82), further confirmed that CCHE1 knockdown inactivates the ERK/MAPK pathway, arresting growth and promoting cell apoptosis.

PAX8-AS1. PAX8-AS1 PAX8 antisense RNA 1 (PAX8-AS1), an important regulator in the upstream region of PAX8 (on chromosome 2q13) (83). PAX8-AS1 contains specific single nucleotide polymorphisms (SNPs), which can represent expression quantitative trait loci (eQTLs) for PAX8. Two eQTLs SNPs (rs4848320 and rs1110839) in PAX8-AS1 decrease the risk of cervical cancer. In addition, PAX8 expression has been recognized as a novel biomarker for fallopian tubes and uterus cancer diagnoses $(84,85)$.

MEG3. The potential function of MEG3 has been studied in a number of cancer types. Downregulation and overexpression of MEG3 alter pituitary tumor cell proliferation, suggesting that MEG3 may be a potential biomarker (86). Likewise, re-expression of MEG3 prevents the proliferation of glioma tumor cells, in vitro (87) and in meningioma (88). Expression of MEG3 is lower in cervical cancer tissue compared with non-neoplastic tissue. In human cervical carcinoma cell lines, high levels of MEG3 inhibit cell proliferation, induce G2/M cell cycle arrest and promote apoptosis (89) via regulation of miR-21-5p. Knockdown of MEG3 results in significant upregulation of miR-21-5p expression in HeLa and CaSki cells (31). These results indicate that MEG3 functions as a tumor suppressor, resulting in the inhibition of tumor growth in cervical cancer.

IncRNA-LET. To the best of our knowledge, there has been only one study examining lncRNA-LET. In that study, low levels of IncRNA-LET expression led to significantly poorer overall survival compared to higher lncRNA-LET expression in patients with cervical cancer. Downregulation of lncRNALET was associated with a poor prognosis in patients with cervical cancer (90). However, more research is necessary in order to elucidate the lncRNA-LET mechanisms associated with cancer.

IncRNA-EBIC. A recent study reported that one-fifth of all human lncRNAs is physically related to polycomb repressive complex 2 (PRC2, comprised of histone H3 lysine 27 methylase EZH2, SUZ12 and EED), suggesting that IncRNAs may play a general role in leading to transcriptional repression by recruiting polycomb-group proteins to their target genes (91). Several lncRNAs have been shown to physically bind to EZH2, such as IncRNA-HEIH, H19 and HOTAIR, and play important roles in regulating cancer epigenetics (14-16). High levels lncRNA-EBIC and EZH2 promote migration and invasion of cervical cancer cells in vitro, resulting in a decrease in E-cadherin expression (13). IncRNA-EBIC has been suggested a key molecule in the migration and invasion of cells and cervical cancer metastasis.

PVT1. Plasmacytoma variant translocation 1 (PVT1) is a highly conserved IncRNA, which is located downstream of MYC (an oncoprotein). PVT1 has attracted great attention due to its frequent co-amplification with MYC in several types of cancer (92-94). In breast and hepatocellular carcinoma, PVT1 function has been attributed to the binding and stabilization of the Myc (18) and Nop2 (95) proteins, respectively. In gastric cancer cells, PVT1 represses the expression of p15 and p16 via co-reaction with EZH2 (14m). Iden et al (24), utilized siRNA and LNA-mediated knockdown for detecting the suppressant effects of low PVT1 levels on cervical cancer cell proliferation, migration and invasion, apoptosis and cisplatin resistance. In contrast, high PVT1 levels were correlated with poorer survival. PVT1 also binds directly to EZH2, recruiting EZH2 to the miR-200b promoter and inhibiting miR-200b expression, which also plays an effective role in regulating the behavior of cervical cancer (17) (Table I).

\section{IncRNAs may act as circulating tumor biomarkers}

It has been demonstrated that many circulating RNAs have diagnostic potential for cancer and are surprisingly stable in blood (96-99). In a study of colorectal cancer, IncRNAs, such as GAS5, HOTAIR, H19 and MEG3 were found in extracellular vesicles (small, phospholipid-enclosed vesicles released by cells into their environment), BCAR4, MEG3 and other 


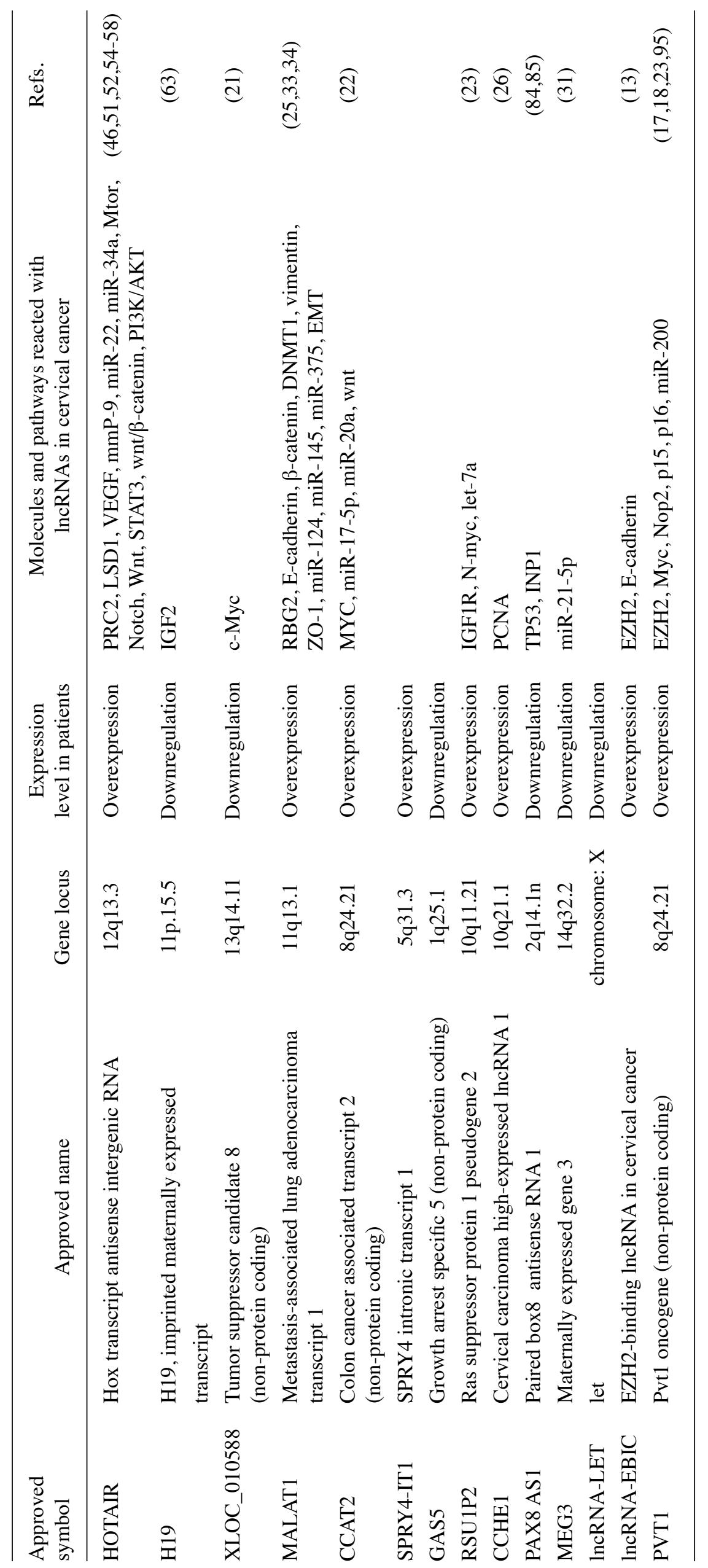




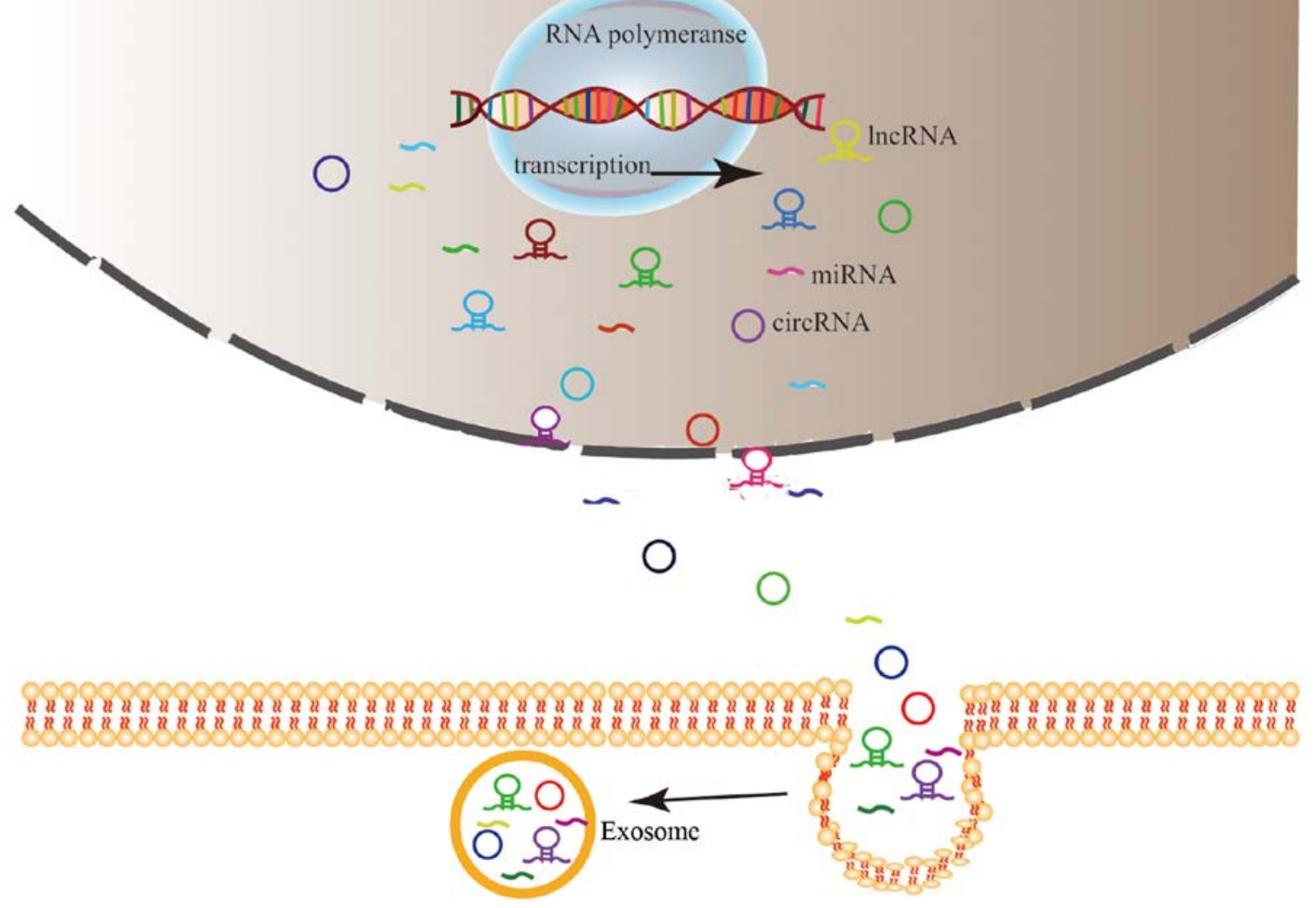

Figure 2. IncRNAs, miRNAs and circRNAs are transcribed in the nucleus and pass through the karyotheca and some go into exosomes. Exosomes with these RNAs play an important role in cervical cancer.

19 lncRNAs were found to be significantly different between the exosomes of samples from healthy people compared to those with colorectal cancer. These have the potential for use as biomarkers for the diagnosis of colorectal cancer (100). In other types of cancer, lncRNAs can be detected in the plasma. PCA3, MALAT-1 and lncRNA-PCAT-18 have been identified as potential biomarkers for patients with metastatic prostate cancer (101-103). It has also been reported that the H19 plasma level was significantly higher, with a sensitivity of $74 \%$ and a specificity of $58 \%$, in patients diagnosed with gastric cancer (GC) compared with healthy controls $(104,105)$. In hepatocellular carcinoma patients the levels of the lncRNAs, HULC, LINC00152, RP11-160H22.5, XLOC_014172, LOC149086 and IncRNA-AF085935 are upregulated in the plasma, particularly lncRNA-AF085935, which was found not only in the plasma from cancer patients, but also in patients infected with hepatitis B (106-109). Only one circulating lncRNA, HOTAIR, has been demonstrated in patients with cervical cancer. Li et al (110), identified plasma HOTAIR overexpression in the serum of cervical cancer patients. However, the study of circulating lncRNAs is new and there are still several challenges, such as finding better ways to collect good quality plasma/serum from whole-blood, handling lncRNA quantification and cancerrelated genes may be expressed highly in cancer tissues, but lower expressed in serum, which must be overcome in order to identify lncRNAs, which can be relied upon as novel, specific and sensitive cancer biomarkers.
Exosomes are identified as important members of circulating tumor biomarkers and can be found in blood, urine and other extracellular fluids $(111,112)$ that contain a large variety of biological components such as proteins, mRNAs, miRNAs and lncRNAs (113). The expression levels of HOTAIR, MALAT1 and MEG3 were significantly different in exosomes isolated from cervical cancer patients compared to those isolated from normal controls (114). Exosomes can also transmit lncARSR, acting as a ceRNA, in renal cancer. The above results indicate that exosome could play a vital role in finding more sensitive and specific circulating tumor biomarkers (Fig. 2).

\section{Conclusion and Prospective}

Although only a few lncRNAs have been functionally characterized, they play a novel role in the regulation of gene expression. In cervical cancer, lncRNAs are important as potential biomarkers for cervical cancer prognosis, invasion, metastasis, chemo-resistance and radio-resistance. At the same time, the IncRNAs interact with circRNA, miRNA, proteins/mRNAs and can be detected in plasma, serum, exosomes and other vesicles in extracellular fluid, which has opened up new avenues for their use as easily accessible biomarkers. However, the potentially significant regulatory mechanisms of lncRNAs in cervical cancer need further exploration and characterization.

Inhibiting oncogenic lncRNA might be the most direct approach for the treatment of cervical cancer. As yet, no RNA 
interference-based drug has been approved; achieving viable and efficient inhibition of IncRNA via siRNAs, miRNAs or by another method, while avoiding side-effects, presents a great challenge and necessitates further study.

\section{Acknowledgements}

The present review was supported by grants from the National Natural Science Foundation of China (81302242), the Jilin Province Science and Technology Funds (20150204007YY and 20130102094JC and 20140204022YY), the Jilin Province Development and Reform Commission Funds (2014G073 and 2016C046-2).

\section{References}

1. Ernst $\mathrm{C}$ and Morton CC: Identification and function of long noncoding RNA. Front Cell Neurosci 7: 168, 2013.

2. Djebali S, Davis CA, Merkel A, Dobin A, Lassmann T, Mortazavi A, Tanzer A, Lagarde J, Lin W, Schlesinger F, et al: Landscape of transcription in human cells. Nature 489: 101-108, 2012.

3. Mercer TR, Dinger ME and Mattick JS: Long non-coding RNAs: Insights into functions. Nat Rev Genet 10: 155-159, 2009.

4. Ling H, Vincent K, Pichler M, Fodde R, Berindan-Neagoe I, Slack FJ and Calin GA: Junk DNA and the long non-coding RNA twist in cancer genetics. Oncogene 34: 5003-5011, 2015.

5. Hauptman N and Glavač D: Long non-coding RNA in cancer. Int J Mol Sci 14: 4655-4669, 2013.

6. Zhang CL: Cidofovir inhibits cervical cancer cell Siha proliferation. Chin Gen M 12: 2012-1024, 2009.

7. Peterson EB, Ostroff JS, DuHamel KN, D'Agostino TA, Hernandez M, Canzona MR and Bylund CL: Impact of providerpatient communication on cancer screening adherence: A systematic review. Prev Med 93: 96-105, 2016.

8. An JS, Huang MN, Song YM, Li N, Wu LY and Zhan QM: A preliminary study of genes related to concomitant chemoradiotherapy resistance in advanced uterine cervical squamous cell carcinoma. Chin Med J (Engl) 126: 4109-4115, 2013.

9. Gadducci A, Tana R, Cosio S and Cionini L: Treatment options in recurrent cervical cancer (Review). Oncol Lett 1: 3-11, 2010.

10. Wang GY, Zhu YY and Zhang YQ: The functional role of long non-coding RNA in digestive system carcinomas. Bull Cancer 101: E27-E31, 2014.

11. Maass PG, Luft FC and Bähring S: Long non-coding RNA in health and disease. J Mol Med (Berl) 92: 337-346, 2014

12. Chen J, Fu Z, Ji C, Gu P, Xu P, Yu N, Kan Y, Wu X, Shen R and Shen Y: Systematic gene microarray analysis of the lncRNA expression profiles in human uterine cervix carcinoma. Biomed Pharmacother 72: 83-90, 2015.

13. Sun NX, Ye C, Zhao Q, Zhang Q, Xu C, Wang SB, Jin ZJ, Sun SH, Wang F and Li W: Long noncoding RNA-EBIC promotes tumor cell invasion by binding to EZH2 and repressing E-cadherin in cervical cancer. PLoS One 9: e100340, 2014.

14. Yang F, Zhang L, Huo XS, Yuan JH, Xu D, Yuan SX, Zhu N, Zhou WP, Yang GS, Wang YZ, et al: Long noncoding RNA high expression in hepatocellular carcinoma facilitates tumor growth through enhancer of zeste homolog 2 in humans. Hepatology 54: 1679-1689, 2011

15. Luo M, Li Z, Wang W, Zeng Y, Liu Z and Qiu J: Long non-coding RNA H19 increases bladder cancer metastasis by associating with EZH2 and inhibiting E-cadherin expression. Cancer Lett 333: 213-221, 2013.

16. Gupta RA, Shah N, Wang KC, Kim J, Horlings HM, Wong DJ, Tsai MC, Hung T, Argani P, Rinn JL, et al: Long non-coding RNA HOTAIR reprograms chromatin state to promote cancer metastasis. Nature 464: 1071-1076, 2010.

17. Zhang S, Zhang G and Liu J: Long noncoding RNA PVT1 promotes cervical cancer progression through epigenetically silencing miR-200b. APMIS 124: 649-658, 2016.

18. Tseng YY, Moriarity BS, Gong W, Akiyama R, Tiwari A, Kawakami H, Ronning P, Reuland B, Guenther K, Beadnell TC, et al: PVT1 dependence in cancer with MYC copy-number increase. Nature 512: 82-86, 2014.
19. Yuan Y, Zhang J, Cai L, Ding C, Wang X, Chen H, Wang X Yan J and Lu J: Leptin induces cell proliferation and reduces cell apoptosis by activating c-myc in cervical cancer. Oncol Rep 29: 2291-2296, 2013

20. Rughooputh S, Manraj S, Eddoo R and Greenwell P: Expression of the c-myc oncogene and the presence of HPV 18: Possible surrogate markers for cervical cancer? Br J Biomed Sci 66: 74-78, 2009.

21. Liao LM, Sun XY, Liu AW, Wu JB, Cheng XL, Lin JX, Zheng M and Huang L: Low expression of long noncoding XLOC_010588 indicates a poor prognosis and promotes proliferation through upregulation of c-Myc in cervical cancer. Gynecol Oncol 133: 616-623, 2014.

22. Ling H, Spizzo R, Atlasi Y, Nicoloso M, Shimizu M, Redis RS, Nishida N, Gafà R, Song J, Guo Z, et al: CCAT2, a novel noncoding RNA mapping to $8 \mathrm{q} 24$, underlies metastatic progression and chromosomal instability in colon cancer. Genome Res 23: 1446-1461, 2013.

23. Liu Q, Guo X, Que S, Yang X, Fan H, Liu M, Li X and Tang H: LncRNA RSU1P2 contributes to tumorigenesis by acting as a ceRNA against let-7a in cervical cancer cells. Oncotarget: Jul 26 2016 (Epub ahead of print). doi: 10.18632/oncotarget.10844.

24. Iden M, Fye S, Li K, Chowdhury T, Ramchandran R and Rader JS: The lncRNA PVT1 contributes to the cervical cancer phenotype and associates with poor patient prognosis. PLoS One 11: e0156274, 2016.

25. Sun R, Qin C, Jiang B, Fang S, Pan X, Peng L, Liu Z, Li W, $\mathrm{Li} \mathrm{Y}$ and Li G: Down-regulation of MALAT1 inhibits cervical cancer cell invasion and metastasis by inhibition of epithelialmesenchymal transition. Mol Biosyst 12: 952-962, 2016.

26. Yang M, Zhai X, Xia B, Wang Y and Lou G: Long noncoding RNA CCHE1 promotes cervical cancer cell proliferation via upregulating PCNA. Tumour Biol 36: 7615-7622, 2015.

27. Salmena L, Poliseno L, Tay Y, Kats L and Pandolfi PP: A ceRNA hypothesis: The Rosetta Stone of a hidden RNA language? Cell 146: 353-358, 2011.

28. Liu XH, Sun M, Nie FQ, Ge YB, Zhang EB, Yin DD, Kong R, Xia R, Lu KH, Li JH, et al: Lnc RNA HOTAIR functions as a competing endogenous RNA to regulate HER 2 expression by sponging miR-331-3p in gastric cancer. Mol Cancer 13: 92, 2014.

29. Yan B, Yao J, Liu JY, Li XM, Wang XQ, Li YJ, Tao ZF, Song YC, Chen $Q$ and Jiang Q: IncRNA-MIAT regulates microvascular dysfunction by functioning as a competing endogenous RNA. Circ Res 116: 1143-1156, 2015.

30. Yuan JH, Yang F, Wang F, Ma JZ, Guo YJ, Tao QF, Liu F, Pan W, Wang TT, Zhou CC, et al: A long noncoding RNA activated by TGF- $\beta$ promotes the invasion-metastasis cascade in hepatocellular carcinoma. Cancer Cell 25: 666-681, 2014.

31. Zhang J, Yao T, Wang Y, Yu J, Liu Y and Lin Z: Long noncoding RNA MEG3 is downregulated in cervical cancer and affects cell proliferation and apoptosis by regulating miR-21. Cancer Biol Ther 17: 104-113, 2016.

32. Lu H, He Y, Lin L, Qi Z, Ma L, Li L and Su Y: Long non-coding RNA MALAT1 modulates radiosensitivity of $\mathrm{HR}^{-\mathrm{HPV}^{+} \text {cervical }}$ cancer via sponging miR-145. Tumour Biol 37: 1683-1691, 2016.

33. Liu S, Song L, Zeng S and Zhang L: MALAT1-miR-124-RBG2 axis is involved in growth and invasion of HR-HPV-positive cervical cancer cells. Tumour Biol 37: 633-640, 2016.

34. Liu S, Song L, Yao H, Zhang L, Xu D, Gao F and Li Q: MiR-375 is epigenetically downregulated by HPV-16 E6 mediated DNMT1 upregulation and modulates EMT of cervical cancer cells by suppressing lncRNA MALAT1. PLoS One 11: e0163460, 2016.

35. Zhang L, Yang F, Yuan JH, Yuan SX, Zhou WP, Huo XS, Xu D, Bi HS, Wang F and Sun SH: Epigenetic activation of the MiR-200 family contributes to H19-mediated metastasis suppression in hepatocellular carcinoma. Carcinogenesis 34: 577-586, 2013.

36. Matouk IJ, Raveh E, Abu-lail R, Mezan S, Gilon M,Gershtain E, Birman T, Gallula J, Schneider T, Barkali M, et al: Oncofetal H19 RNA promotes tumor metastasis. Biochim Biophys Acta 1843: 1414-1426, 2014.

37. Zhao H, Peng R, Liu Q, Liu D, Du P, Yuan J, Peng G and Liao Y: The IncRNA H19 interacts with miR-140 to modulate glioma growth by targeting iASPP. Arch Biochem Biophys 610: 1-7, 2016.

38. Huang M,Zhong Z,Lv M,Shu J,Tian Q and Chen J:Comprehensive analysis of differentially expressed profiles of lncRNAs and circRNAs with associated co-expression and ceRNA networks in bladder carcinoma. Oncotarget 7: 47186-47200, 2016. 
39. Bosch FX, Manos MM, Muñoz N, Sherman M, Jansen AM, Peto J, Schiffman MH, Moreno V, Kurman R and Shah KV: Prevalence of human papillomavirus in cervical cancer: A worldwide perspective. International biological study on cervical cancer (IBSCC) Study Group. J Natl Cancer Inst 87: 796-802, 1995.

40. Greco D, Kivi N, Qian K, Leivonen SK, Auvinen P and Auvinen E: Human papillomavirus 16 E5 modulates the expression of host microRNAs. PLoS One 6: e21646, 2011.

41. Sasagawa T, Takagi $\mathrm{H}$ and Makinoda S: Immune responses against human papillomavirus (HPV) infection and evasion of host defense in cervical cancer. J Infect Chemother 18: 807-815, 2012.

42. Khorasanizadeh F, Hassanloo J, Khaksar N, Mohammad Taheri S, Marzaban M, H Rashidi B, Akbari Sari A and Zendehdel K: Epidemiology of cervical cancer and human papilloma virus infection among Iranian women - analyses of national data and systematic review of the literature. Gynecol Oncol 128: 277-281, 2013.

43. Sharma S, Mandal P, Sadhukhan T, Roy Chowdhury R, Ranjan Mondal N, Chakravarty B, Chatterjee T, Roy S and Sengupta S: Bridging links between long noncoding RNA HOTAIR and HPV oncoprotein e7 in cervical cancer pathogenesis. Sci Rep 5: 11724, 2015.

44. Leung CO, Deng W, Ye TM, Ngan HY, Tsao SW, Cheung AN Pang RT and Yeung WS: miR-135a leads to cervical cancer cell transformation through regulation of $\beta$-catenin via a SIAH1dependent ubiquitin proteosomal pathway. Carcinogenesis 35 : 1931-1940, 2014

45. Rinn JL, Kertesz M, Wang JK, Squazzo SL, Xu X, Brugmann SA, Goodnough LH, Helms JA, Farnham PJ, Segal E, et al: Functional demarcation of active and silent chromatin domains in human HOX loci by noncoding RNAs. Cell 129: 1311-1323, 2007.

46. Kim HJ, Lee DW, Yim GW, Nam EJ, Kim S, Kim SW and Kim YT: Long non-coding RNA HOTAIR is associated with human cervical cancer progression. Int J Oncol 46: 521-530, 2015.

47. Huang L, Liao LM, Liu AW, Wu JB, Cheng XL, Lin JX and Zheng M: Overexpression of long noncoding RNA HOTAIR predicts a poor prognosis in patients with cervical cancer. Arch Gynecol Obstet 290: 717-723, 2014.

48. Guo L, Lu X, Zheng L, Liu X and Hu M: Association of long non-coding RNA HOTAIR polymorphisms with cervical cancer risk in a chinese population. PLoS One 11: e0160039, 2016.

49. Sweta Sharma S, Rahul Roy C and Nidhu Ranjan M: Identification of genetic variation in the lncRNA HOTAIR associated with HPV16-related cervical cancer pathogenesis. Cell Oncol 9: 28, 2016.

50. Guertin DA and Sabatini DM: Defining the role of mTOR in cancer. Cancer Cell 12: 9-22, 2007.

51. Zhang D, Zhou XH, Zhang J, Zhou YX, Ying J, Wu GQ and Qian JH: Propofol promotes cell apoptosis via inhibiting HOTAIR mediated mTOR pathway in cervical cancer. Biochem Biophys Res Commun 468: 561-567, 2015.

52. Lee M, Kim HJ, Kim SW, Park SA, Chun KH, Cho NH, Song YS and Kim YT: The long non-coding RNA HOTAIR increases tumour growth and invasion in cervical cancer by targeting the Notch pathway. Oncotarget 7: 44558-44571, 2016.

53. Jing L, Yuan W, Ruofan D, Jinjin Y and Haifeng Q: HOTAIR enhanced aggressive biological behaviors and induced radioresistance via inhibiting p21 in cervical cancer. Tumour Biol 36 : 3611-3619, 2015.

54. Li L, Liu B, Wapinski OL, Tsai MC, Qu K, Zhang J, Carlson JC, Lin M, Fang F, Gupta RA, et al: Targeted disruption of Hotair leads to homeotic transformation and gene derepression. Cell Rep 5: 3-12, 2013.

55. Ding C, Cheng S, Yang Z, Lv Z, Xiao H, Du C, Peng C, Xie H, Zhou L, Wu J, et al: Long non-coding RNA HOTAIR promotes cell migration and invasion via down-regulation of RNA binding motif protein 38 in hepatocellular carcinoma cells. Int J Mol Sci 15: 4060-4076, 2014

56. Li D, Feng J, Wu T, Wang Y, Sun Y, Ren J and Liu M: Long intergenic noncoding RNA HOTAIR is overexpressed and regulates PTEN methylation in laryngeal squamous cell carcinoma. Am J Pathol 182: 64-70, 2013

57. Zhang H, Cai K, Wang J, Wang X, Cheng K, Shi F, Jiang L, Zhang Y and Dou J: MiR-7, inhibited indirectly by lincRNA HOTAIR, directly inhibits SETDB1 and reverses the EMT of breast cancer stem cells by downregulating the STAT3 pathway. Stem Cells 32: 2858-2868, 2014.
58. Carrion K, Dyo J, Patel V, Sasik R, Mohamed SA, Hardiman G and Nigam V: The long non-coding HOTAIR is modulated by cyclic stretch and WNT/ $\beta$-CATENIN in human aortic valve cells and is a novel repressor of calcification genes. PLoS One 9: e96577, 2014.

59. Kallen AN, Zhou XB, Xu J, Qiao C, Ma J, Yan L, Lu L, Liu C, Yi JS, Zhang H, et al: The imprinted H19 lncRNA antagonizes let-7 microRNAs. Mol Cell 52: 101-112, 2013.

60. Matouk IJ, DeGroot N, Mezan S, Ayesh S, Abu-lail R, Hochberg A and Galun E: The H19 non-coding RNA is essential for human tumor growth. PLoS One 2: e845, 2007.

61. Lee DF, Su J, Kim HS, Chang B, Papatsenko D, Zhao R, Yuan Y, Gingold J, Xia W, Darr H, et al: Modeling familial cancer with induced pluripotent stem cells. Cell 161: 240-254, 2015.

62. Yoshimizu T, Miroglio A, Ripoche MA, Gabory A, Vernucci M, Riccio A, Colnot S, Godard C, Terris B, Jammes H, et al: The H19 locus acts in vivo as a tumor suppressor. Proc Natl Acad Sci USA 105: 12417-12422, 2008.

63. Kim SJ, Park SE, Lee C, Lee SY, Jo JH, Kim JM and Oh YK: Alterations in promoter usage and expression levels of insulinlike growth factor-II and H19 genes in cervical carcinoma exhibiting biallelic expression of IGF-II. Biochim Biophys Acta 1586: 307-315, 2002

64. Tripathi V, Ellis JD, Shen Z, Song DY, Pan Q, Watt AT, Freier SM, Bennett CF, Sharma A, Bubulya PA, et al: The nuclear-retained noncoding RNA MALAT1 regulates alternative splicing by modulating SR splicing factor phosphorylation. Mol Cell 39: 925-938, 2010

65. Yang L, Bai HS, Deng Y and Fan L: High MALAT1 expression predicts a poor prognosis of cervical cancer and promotes cancer cell growth and invasion. Eur Rev Med Pharmacol Sci 19: 3187-3193, 2015

66. Redis RS, Sieuwerts AM, Look MP, Tudoran O, Ivan C, Spizzo R, Zhang X, de Weerd V, Shimizu M, Ling H, et al: CCAT2, a novel long non-coding RNA in breast cancer: Expression study and clinical correlations. Oncotarget 4: 1748-1762, 2013.

67. Wu L, Jin L, Zhang W and Zhang L: Roles of long non-coding RNA CCAT2 in cervical cancer cell growth and apoptosis. Med Sci Monit 22: 875-879, 2016.

68. Chen X, Liu L and Zhu W: Up-regulation of long non-coding RNA CCAT2 correlates with tumor metastasis and poor prognosis in cervical squamous cell cancer patients. Int J Clin Exp Pathol 8: 13261-13266, 2015.

69. Khaitan D, Dinger ME, Mazar J, Crawford J, Smith MA, Mattick JS and Perera RJ: The melanoma-upregulated long noncoding RNA SPRY4-IT1 modulates apoptosis and invasion. Cancer Res 71: 3852-3862, 2011.

70. Liu T, Shen SK, Xiong JG, Xu Y, Zhang HQ, Liu HJ and Lu ZG: Clinical significance of long noncoding RNA SPRY4-IT1 in melanoma patients. FEBS Open Bio 6: 147-154, 2016.

71. Xie M, Nie FQ, Sun M, Xia R, Liu YW, Zhou P, De W and Liu XH: Decreased long noncoding RNA SPRY4-IT1 contributing to gastric cancer cell metastasis partly via affecting epithelial-mesenchymal transition. J Transl Med 13: 250, 2015.

72. Sun M, Liu XH, Lu KH, Nie FQ, Xia R, Kong R, Yang JS, Xu TP Liu YW,Zou YF, et al: EZH2-mediated epigenetic suppression of long noncoding RNA SPRY4-IT1 promotes NSCLC cell proliferation and metastasis by affecting the epithelial-mesenchymal transition. Cell Death Dis 5: e1298, 2014.

73. Xie HW, Wu QQ, Zhu B, Chen FJ, Ji L, Li SQ, Wang CM, Tong YS, Tuo L, Wu M, et al: Long noncoding RNA SPRY4-IT1 is upregulated in esophageal squamous cell carcinoma and associated with poor prognosis. Tumour Biol 35: 7743-7754, 2014

74. Peng W, Wu G, Fan H, Wu J and Feng J: Long noncoding RNA SPRY4-IT1 predicts poor patient prognosis and promotes tumorigenesis in gastric cancer. Tumour Biol 36: 6751-6758, 2015.

75. Zhao XL, Zhao ZH, Xu WC, Hou JQ and Du XY: Increased expression of SPRY4-IT1 predicts poor prognosis and promotes tumor growth and metastasis in bladder cancer. Int J Clin Exp Pathol 8: 1954-1960, 2015.

76. Zhang HM, Yang FQ, Yan Y, Che JP and Zheng JH: High expression of long non-coding RNA SPRY4-IT1 predicts poor prognosis of clear cell renal cell carcinoma. Int J Clin Exp Pathol 7: 5801-5809, 2014

77. Cao Y, Liu Y, Lu X, Wang Y, Qiao H and Liu M: Upregulation of long noncoding RNA SPRY4-IT1 correlates with tumor progression and poor prognosis in cervical cancer. FEBS Open Bio 6: 954-960, 2016. 
78. Wu Y, Lyu H, Liu H, Shi X, Song Y and Liu B: Downregulation of the long noncoding RNA GAS5-AS1 contributes to tumor metastasis in non-small cell lung cancer. Sci Rep 6: 31093, 2016.

79. Liang W, Lv T, Shi X, Liu H, Zhu Q, Zeng J, Yang W, Yin J and Song Y: Circulating long noncoding RNA GAS5 is a novel biomarker for the diagnosis of nonsmall cell lung cancer. Medicine (Baltimore) 95: e4608, 2016.

80. Zhang N, Wang AY, Wang XK, Sun XM and Xue HZ: GAS5 is downregulated in gastric cancer cells by promoter hypermethylation and regulates adriamycin sensitivity. Eur Rev Med Pharmacol Sci 20: 3199-3205, 2016.

81. Cao S, Liu W, Li F, Zhao W and Qin C: Decreased expression of lncRNA GAS5 predicts a poor prognosis in cervical cancer. Int J Clin Exp Pathol 7: 6776-6783, 2014

82. Peng $\mathrm{W}$ and Fan $\mathrm{H}$ : Long noncoding RNA CCHE1 indicates a poor prognosis of hepatocellular carcinoma and promotes carcinogenesis via activation of the ERK/MAPK pathway. Biomed Pharmacother 83: 450-455, 2016.

83. Han J, Zhou W, Jia M, Wen J, Jiang J, Shi J, Zhang K, Ma H, Liu J, Ren J, et al: Expression quantitative trait loci in long noncoding RNA PAX8-AS1 are associated with decreased risk of cervical cancer. Mol Genet Genomics 291: 1743-1748, 2016.

84. Tacha D, Zhou D and Cheng L: Expression of PAX8 in normal and neoplastic tissues: A comprehensive immunohistochemical study. Appl Immunohistochem Mol Morphol 19: 293-299, 2011.

85. Waters L, Crumley S, Truong L, Mody D and Coffey D: PAX2 and PAX8: Useful markers for metastatic effusions. Acta Cytol 58: $60-66,2014$

86. Zhou Y, Zhang X and Klibanski A: MEG3 noncoding RNA: A tumor suppressor. J Mol Endocrinol 48: R45-R53, 2012.

87. Wang $P$, Ren $Z$ and Sun P: Overexpression of the long noncoding RNA MEG3 impairs in vitro glioma cell proliferation. J Cell Biochem 113: 1868-1874, 2012.

88. Zhang X, Gejman R, Mahta A, Zhong Y, Rice KA, Zhou Y, Cheunsuchon P, Louis DN and Klibanski A: Maternally expressed gene 3, an imprinted noncoding RNA gene, is associated with meningioma pathogenesis and progression. Cancer Res 70: 2350-2358, 2010.

89. Qin R, Chen Z, Ding Y, Hao J, Hu J and Guo F: Long non-coding RNA MEG3 inhibits the proliferation of cervical carcinoma cells through the induction of cell cycle arrest and apoptosis. Neoplasma 60: 486-492, 2013.

90. Jiang S, Wang HL and Yang J: Low expression of long noncoding RNA LET inhibits carcinogenesis of cervical cancer. Int J Clin Exp Pathol 8: 806-811, 2015.

91. Khalil AM, Guttman M, Huarte M, Garber M, Raj A, Rivea Morales D, Thomas K, Presser A, Bernstein BE, van Oudenaarden A, et al: Many human large intergenic noncoding RNAs associate with chromatin-modifying complexes and affect gene expression. Proc Natl Acad Sci USA 106: 1166711672,2009

92. Guan Y, Kuo WL, Stilwell JL, Takano H, Lapuk AV, Fridlyand J, Mao JH, Yu M, Miller MA, Santos JL, et al: Amplification of PVT1 contributes to the pathophysiology of ovarian and breast cancer. Clin Cancer Res 13: 5745-5755, 2007.

93. Barsotti AM1, Beckerman R, Laptenko O, Huppi K, Caplen NJ and Prives C: P53-dependent induction of PVT1 and miR-1204. J Biol Chem 287: 2509-2519, 2012.

94. Paci P, Colombo T and Farina L: Computational analysis identifies a sponge interaction network between long non-coding RNAs and messenger RNAs in human breast cancer. BMC Syst Biol 8: 83, 2014

95. Kong R, Zhang EB, Yin DD, You LH, Xu TP, Chen WM, Xia R, Wan L, Sun M, Wang ZX, et al: Long noncoding RNA PVT1 indicates a poor prognosis of gastric cancer and promotes cell proliferation through epigenetically regulating $\mathrm{p} 15$ and $\mathrm{p} 16 . \mathrm{Mol}$ Cancer 14: 82, 2015.

96. Dong L, Qi P, Xu MD, Ni SJ, Huang D, Xu QH, Weng WW, Tan C, Sheng WQ, Zhou XY, et al: Circulating CUDR, LSINCT-5 and PTENP1 long noncoding RNAs in sera distinguish patients with gastric cancer from healthy controls. Int J Cancer 137: 1128-1135, 2015 .
97. Ronnau CG, Verhaegh GW, Luna-Velez MV and Schalken JA Noncoding RNAs as novel biomarkers in prostate cancer. BioMed Res Int 2014: 591703, 2014. https://doi.org/10.1155/2014/591703.

98. Isin M, Ozgur E, Cetin G, Erten N, Aktan M, Gezer U and Dalay N: Investigation of circulating lncRNAs in B-cell neoplasms. Clin Chim Acta 431: 255-259, 2014.

99. Lorenzen JM, Schauerte C, Kielstein JT, Hübner A, Martino F, Fiedler J, Gupta SK, Faulhaber-Walter R, Kumarswamy R, Hafer C, et al: Circulating long noncoding RNATapSaki is a predictor of mortality in critically ill patients with acute kidney injury. Clin Chem 61: 191-201, 2015.

100. Dong L, Lin W, Qi P, Xu MD, Wu X, Ni S, Huang D, Weng WW, Tan C, Sheng W, et al: Circulating long RNAs in serum extracellular vesicles: Their characterization and potential application as biomarkers for diagnosis of colorectal cancer. Cancer Epidemiol Biomarkers Prev 25: 1158-1166, 2016.

101. Wang F, Ren S, Chen R, Lu J, Shi X, Zhu Y, Zhang W, Jing T, Zhang C, Shen J, et al: Development and prospective multicenter evaluation of the long noncoding RNA MALAT-1 as a diagnostic urinary biomarker for prostate cancer. Oncotarget 5: 11091-11102, 2014

102. Crea F, Watahiki A, Quagliata L, Xue H, Pikor L, Parolia A, Wang Y, Lin D, Lam WL, Farrar WL, et al: Identification of a long non-coding RNA as a novel biomarker and potential therapeutic target for metastatic prostate cancer. Oncotarget 5: 764-774, 2014

103. Merola R, Tomao L, Antenucci A, Sperduti I, Sentinelli S, Masi S, Mandoj C, Orlandi G, Papalia R, Guaglianone S, et al: PCA3 in prostate cancer and tumor aggressiveness detection on 407 high-risk patients: A National Cancer Institute experience. J Exp Clin Cancer Res 34: 15, 2015.

104. Arita T, Ichikawa D, Konishi H, Komatsu S, Shiozaki A, Shoda K, Kawaguchi T, Hirajima S, Nagata H, Kubota T, et al: Circulating long non-coding RNAs in plasma of patients with gastric cancer. Anticancer Res 33: 3185-3193, 2013.

105. Zhou X, Yin C, Dang Y, Ye F and Zhang G: Identification of the long non-coding RNA H19 in plasma as a novel biomarker for diagnosis of gastric cancer. Sci Rep 5: 11516, 2015.

106. Xie H, Ma H and Zhou D: Plasma HULC as a promising novel biomarker for the detection of hepatocellular carcinoma. BioMed Res Int 2013: 136106, 2013. https://doi.org/10.1155/2013/136106.

107. Lu J, Xie F, Geng L, Shen W, Sui C and Yang J: Investigation of serum IncRNA-uc003wbd and lncRNA-AF085935 expression profile in patients with hepatocellular carcinoma and $\mathrm{HBV}$. Tumour Biol 36: 3231-3236, 2015.

108. Tang J, Jiang R, Deng L, Zhang X, Wang K and Sun B: Circulation long non-coding RNAs act as biomarkers for predicting tumorigenesis and metastasis in hepatocellular carcinoma. Oncotarget 6: 4505-4515, 2015

109. Li J, Wang X, Tang J, Jiang R, Zhang W, Ji J and Sun B: HULC and Linc00152 act as novel biomarkers in predicting diagnosis of hepatocellular carcinoma. Cell Physiol Biochem 37: 687-696, 2015.

110. Li J, Wang Y, Yu J, Dong R and Qiu H: A high level of circulating HOTAIR is associated with progression and poor prognosis of cervical cancer. Tumour Biol 36: 1661-1665, 2015.

111. Ahadi A, Brennan S, Kennedy PJ, Hutvagner G and Tran N: Long non-coding RNAs harboring miRNA seed regions are enriched in prostate cancer exosomes. Sci Rep 6: 24922, 2016.

112. Berrondo C, Flax J, Kucherov V, Siebert A, Osinski T, Rosenberg A, Fucile C, Richheimer S and Beckham CJ: Expression of the long non-coding RNA HOTAIR correlates with disease progression in bladder cancer and is contained in bladder cancer patient urinary exosomes. PLoS One 11: e0147236, 2016

113. Wang J, Zhou Y, Lu J, Sun Y, Xiao H, Liu M and Tian L: Combined detection of serum exosomal miR-21 and HOTAIR as diagnostic and prognostic biomarkers for laryngeal squamous cell carcinoma. Med Oncol 31: 148, 2014

114. Zhang J, Liu SC, Luo XH, Tao GX, Guan M, Yuan H and Hu DK: Exosomal long noncoding RNAs are differentially expressed in the cervicovaginal lavage samples of cervical cancer patients. J Clin Lab Anal 30: 1116-1121, 2016. 